\title{
A shape-adaptable organometallic supramolecular coordination cage for the encapsulation of fullerenes
}

\author{
Víctor Martínez-Agramunt, ${ }^{[a]}$ Dmitry G. Gusev ${ }^{[b]}$ and Eduardo Peris ${ }^{*[a]}$
}

\begin{abstract}
The development of three dimensional supramolecular coordination complexes (SCCs) with cavities suitable for guest binding is of great interest because these materials are useful in a large number of applications. Herein, we describe a nickel-conjoined organometallic molecular prism, which has been fully characterized. The X-ray diffraction structure of the molecule reveals that the cage possesses an internal cavity with a volume of $1028 \AA^{3}$, thus suitable for the encapsulation of large 3D-molecules, such as fullerenes. This cage shows highly selective complexation of $\mathrm{C}_{70}$ over $\mathrm{C}_{60}$, thus being potentially useful for fullerene separation and purification. The combined experimental and computational studies suggest that the complexation process is largely entropically-driven, and that the cage is flexible and can adapt the size and the shape of the cavity to maximize the face-to-face interaction with the fullerenes.
\end{abstract}

\section{Introduction}

The rich coordination chemistry of transition metals and the availability of a large number of organic ligands have provided access to many two- and three-dimensional metallosupramolecular architectures with applications in catalysis,${ }^{[1]}$ molecular recognition, ${ }^{[2]}$ for stabilizing highly reactive species, ${ }^{[3]}$ and as drug delivery/release vectors. ${ }^{[4]}$ Of particular interest are supramolecular coordination complexes (SCCs) with well-defined cavities suitable for guest binding ${ }^{[5]}$; the host-guest chemistry arguably being the most important feature of SCCs, from which most applications can be derived. In particular, the selective encapsulation of large aromatic compounds, such as fullerenes ${ }^{[6]}$ and polycyclic aromatic hydrocarbons $(\mathrm{PAHs})^{[7]}$ is of increasing interest since it may provide practical solutions for the purification of molecules which otherwise would be very difficult to separate due to their similar physicochemical properties.

While most of the known metallosupramolecular structures are Werner-type coordination complexes, in the last five years a number of organometallic supramolecular architectures have emerged, most of them based on the use of $\mathrm{N}$-heterocyclic carbenes (NHCs) ${ }^{[8]}$ However, due to the scarcity of ligands of the appropriate sizes, most known organometallic metallosupramolecules are too small to host organic molecules, and this explains why organometallic host-guest chemistry is rare. Advancing organometallic host-guest chemistry is possible

[a] Víctor Martínez-Agramunt and Prof. Eduardo Peris

Institute of Advanced Materials (INAM). Universitat Jaume I. Av. Vicente

Sos Baynat s/n. Castellón. E-1271. Spain. Email: eperis@uji.es

[b] Prof. D. G. Gusev

Dept. of Chemistry and Biochemistry, Wilfrid Laurier University,

Waterloo, Ontario N2L 3C5 (Canada). Email: dgoussev@wlu.ca

Supporting information for this article is given via a link at the end of the document.((Please delete this text if not appropriate)) through the development of poly-NHC ligands that mimic the supramolecular architectures facilitated by Werner-type ligands, thus allowing the preparation of arguably more stable organometallic assemblies supported by the strong NHC-M bonds. By designing a series of $\mathrm{NHC}$ ligands decorated with rigid polyaromatic functionalities, ${ }^{[9]}$ we recently gained access to a number of organometallic supramolecular complexes, which we used for the recognition of different organic molecules ${ }^{[6,, 7 i, 10]}$ and metal cations. ${ }^{[11]}$ In one of our approaches, we formed two nickelcornered molecular rectangles using a pyrene-bisimidazolylidene ligand (B and $\mathbf{C}$, Scheme 1). ${ }^{[7]}$ The twodimensional complexes $\mathbf{B}$ and $\mathbf{C}$ resemble the previously reported molecular rectangle $\mathbf{A}$, described by Hahn and co-workers in 2008 ${ }^{[12]}$ However, while $\mathbf{A}$ was unsuitable even for the recognition of the smaller PAHs due to the relatively short separation provided by the benzoimidazolylidene ligand (10.4 $\AA$ ), B and $\mathbf{C}$ served as effective receptors and scavengers of a range of polyaromatic molecules, due to the longer separation provided by the pyrenebisimidazolylidene ligand $(13 \AA)$, and due to the effective steric and electronic complementarity. We recently became interested in obtaining a three-dimensional molecular cage based on the same organometallic supramolecular motif as the one used in B and $\mathbf{C}$. We envisaged that, if $\mathbf{B}$ and $\mathbf{C}$ were able to effectively encapsulate two-dimensional organic molecules by multiple synergistic aromatic interactions, a related three-dimensional cage should be able to recognize 3-D organic molecules, such as fullerenes. Additionally, we hypothesized that a relatively rigid organometallic supramolecular cage should render sizedependent selective complexation of fullerenes. Finding systems for the selective encapsulation of fullerenes, ${ }^{[6]}$ and especially finding receptors for the selective complexation of $\mathrm{C}_{70}$ over $\mathrm{C}_{60}$, is a challenging field of research that continuous to gain interest. In this communication, we describe the preparation of a threedimensional nickel-cornered trigonal prism constituted by pyrenedi-imidazolylidene and 1,3,5-tripyridyl-triazine (TPT) ligands. This cage shows highly selective complexation of $\mathrm{C}_{70}$ over $\mathrm{C}_{60}$.

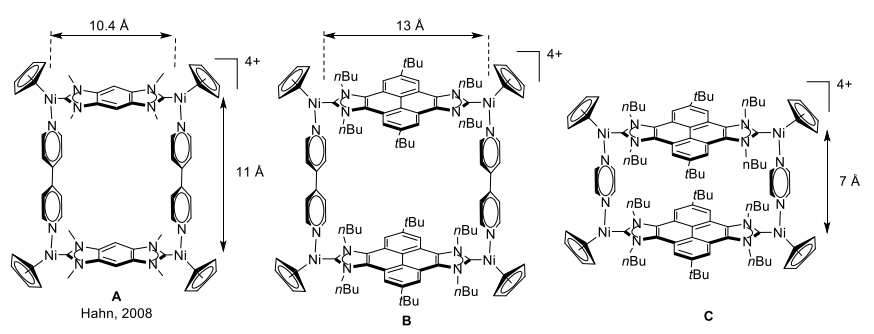

Scheme 1. Nickel-conjoined molecular rectangles 


\section{Results and discussion}

The reaction of the bis-nickel-pyrene-di-imidazolylidene complex 1 with TPT and two equivalents of $\mathrm{AgBF}_{4}$ in dichloromethane afforded the air-stable metallocage 2 as a red solid, in $60 \%$ yield after purification (Scheme 2). The hexametallic complex 2 was characterized by NMR spectroscopy, mass spectrometry and elemental analysis. The correct stoichiometry of the cage was confirmed by ESI-TOF-MS, which showed peaks at $\mathrm{m} / \mathrm{z} 1161.2$ and 1785.2 assigned to $\left[2-3 \mathrm{BF}_{4}\right]^{3+}$ and $\left[2-2 \mathrm{BF}_{4}\right]^{4+}$, respectively. The formation of a single assembly was further confirmed by Diffusion-ordered NMR spectroscopy (DOSY), which revealed that all the proton signals showed the same diffusion coefficient in deuterated acetone $2.7 \times 10^{-10} \mathrm{~m}^{2} \mathrm{~s}^{-1}$ (see SI for details). By using the Stokes-Einstein equation, this coefficient provides an estimated hydrodynamic radius of $6.2 \AA$, in a good agreement with the expected radius of 2 based on the known size of the bis-NHC and TPT ligands.
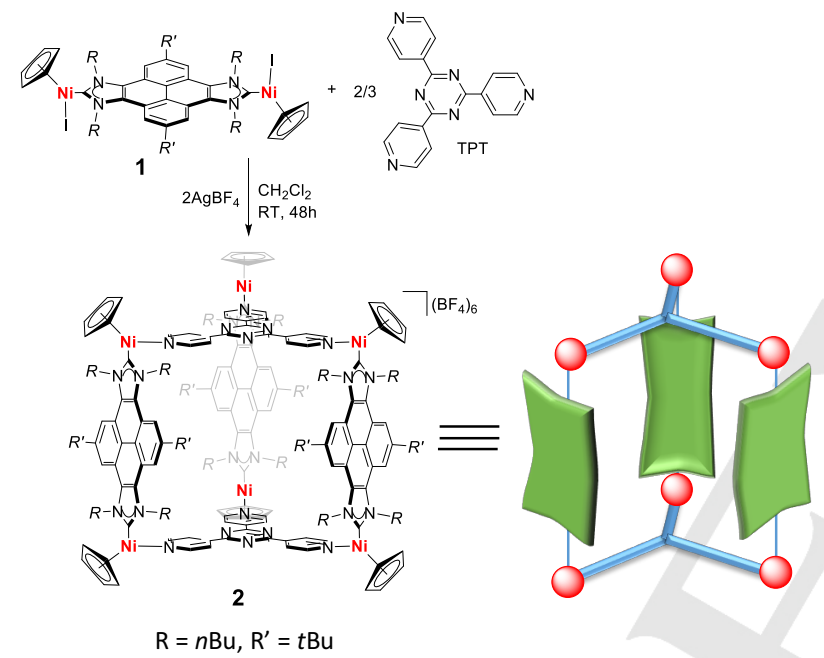

Scheme 2. Synthesis of metallocage 2

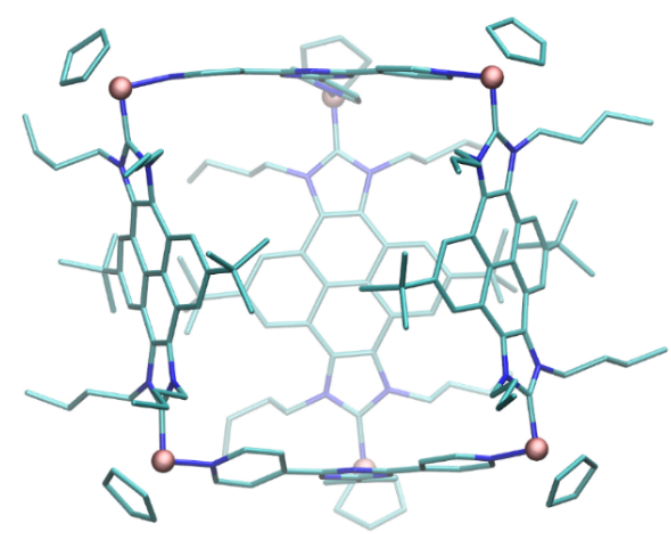

Figure 1. X-Ray molecular structure of 2 . The counter-anions $\left(6 \mathrm{BF}_{4}{ }^{-}\right)$and solvent (dichloroethane) are omitted for clarity.

The molecular structure of 2 was determined by X-ray diffraction (Figure 1). The molecule contains six nickel atoms connected by two TPT ligands and three pyrene-di-imidazolylidenes, thus forming a trigonal prism with pseudo- $D_{3 \mathrm{~h}}$ symmetry. The central pyrene fragments of the bis-NHC ligands are bent along the corresponding $\mathrm{Ni}-\mathrm{Ni}$ axis, resulting in a convex curvature with respect to the inner cavity of the cage. The same pyrene fragments also show a concave curvature along the axis defined by the corresponding tert-butyl groups. These two distortions make the trigonal prism look as if tied around by an imaginary belt, as reflected by the average distance between the centroid of the cage and the two central carbons of the pyrenes $(6.89 \AA)$, and the average distance between the centroid of the TPT ligand and the nickel atoms $(7.43 \AA)$. The average $\mathrm{Ni}-\mathrm{Ni}$ through-space distance across the bis-NHC ligand is $12.93 \AA$, that is practically the same as the average $\mathrm{Ni}-\mathrm{Ni}$ distance along the triangular face of the prism, $12.86 \AA$. The effective size of the central cavity ${ }^{[13]}$ is 1028 $\AA^{3}$.

Considering the size of the internal cavity of $\mathbf{2}$ and the polyaromatic nature of its surface, we envisioned that this molecule might be a good system for studying supramolecular binding of fullerenes. We first performed an experiment that involved dissolving 2 in acetone- $d_{6}$ in the presence of a suspension of $\mathrm{C}_{60}$ in an NMR tube. The product mixture was sonicated at room temperature, and changes in the sample were followed by ${ }^{1} \mathrm{H}$ NMR spectroscopy. In this experiment we took advantage of the high solubility of $\mathbf{2}$ in acetone, the solvent where $\mathrm{C}_{60}$ is practically insoluble, so that the fullerene could become NMR-observable only if captured by the metallocage.

As can be seen from the spectra presented in Figure 2, we initially observed the ${ }^{1} \mathrm{H}$ NMR spectrum of the empty molecular cage 2. After $1 \mathrm{~h}$, a new species appeared in the spectrum, attributed to the formation of a host-guest complex $\mathrm{C}_{60} @ 2$. The signal due to the protons of the pyrene-connecting group of the di-NHC ligand is upfield shifted with respect to the related signal of the empty cage. In addition, the signals due to the protons of the TPT ligand are downfield shifted with respect to the corresponding resonances of 2 . These observations are consistent with the fullerene being accommodated inside the cavity of $\mathbf{2}$ and interacting via $\pi$-stacking with the internal polyaromatic surface of the cage. The spectrum recorded after $8 \mathrm{~h}$ of reaction showed only the signals due to the $\mathrm{C}_{60} @ 2$ adduct, therefore indicating that the conversion was complete. A similar experiment was carried out using $\mathrm{C}_{70}$ and provided similar results, affording clear evidence of formation of a $\mathrm{C}_{70} @ 2$ complex (see ESI for details).

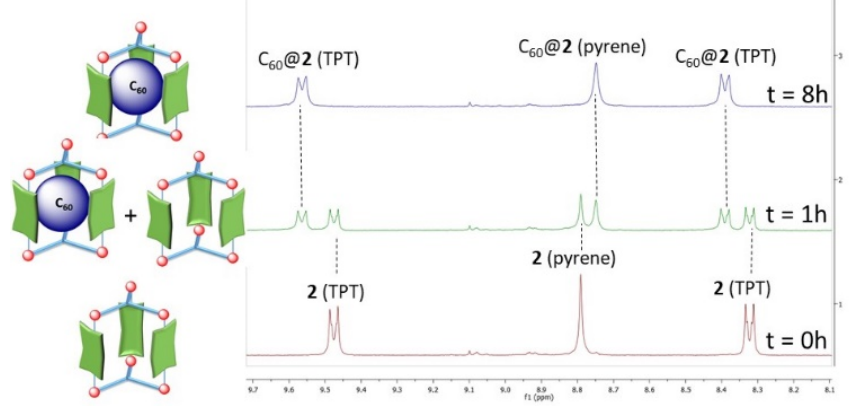

Figure 2. The aromatic region of ${ }^{1} \mathrm{H}$ NMR spectra of a mixture of $\mathbf{2}$ with $\mathrm{C}_{60}$ in acetone- $d_{6}$. The spectra were recorded immediately after mixing, and 1 and $8 \mathrm{~h}$ later). 
These experiments allowed us to isolate $\mathrm{C}_{60} @ 2$ and $\mathrm{C}_{70} @ 2$, by simply filtering off the remaining insoluble fullerenes, followed by solvent evaporation. The ${ }^{13} \mathrm{C}$ NMR spectra of the isolated $\mathrm{C}_{60} @ 2$ and $C_{70} @ 2$ in acetone- $d_{6}$ displayed the characteristic signals due to the carbons of the fullerenes (see ESI for full details).

For the determination of the binding constants we found that a mixture of acetone/dichlorobenzene (1:4) provided the best solubilities for both the host and the guests. By using this solvent mixture, we observed that exchange of the free and bound host signals was slow on the NMR timescale, so integration of the distinct signals of free $\mathbf{2}$ and the complexes fullerene@2 was used to calculate the equilibrium constants. This way, we obtained the binding constants of $4.7 \times 10^{3}$ and $3.5 \times 10^{4} \mathrm{M}^{-1}$, for the encapsulation of $\mathrm{C}_{60}$ and $\mathrm{C}_{70}$ at room temperature, respectively. This result indicates a preferred complexation of $\mathrm{C}_{70}$ over $\mathrm{C}_{60}$ of about one order of magnitude. The constants obtained are very large, especially considering that they were obtained using a mixture of solvents containing $80 \%$ dichlorobenzene, a good solvent for fullerenes for which lower association constants are often observed. ${ }^{[14]}$
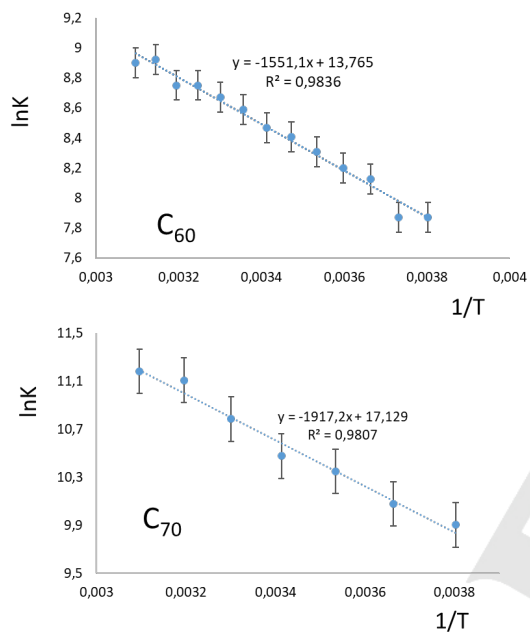

Figure 3. Plots of InK vs. 1/T. The plots were built by using the binding constants obtained from the ${ }^{1} \mathrm{H}$ NMR spectra taken at different temperatures, from equimolar solutions $(0.3 \mathrm{mM})$ of 2 and fullerene in acetone- $d_{6}$ :dichlorobenzene$d_{4} 1$ :4. Error bands assume uncertainties of $10 \%\left(C_{60}\right)$ and $20 \%\left(C_{70}\right)$ in binding constant values.

By recording variable-temperature ${ }^{1} \mathrm{H}$ NMR spectra, we obtained a series of binding constants that allowed us to determine the association enthalpies and entropies from the related Van't Hoff plots (Figure 3 ). The thermodynamic values obtained for the association of $\mathrm{C}_{60}$ were $\Delta \mathrm{H}=3.1 \mathrm{kcal} / \mathrm{mol}$ and $\Delta S=27 \mathrm{cal} / \mathrm{molK}$. For $\mathrm{C}_{70}$, the values were $\Delta \mathrm{H}=3.8 \mathrm{kcal} / \mathrm{mol}$ and $\Delta S=34 \mathrm{cal} / \mathrm{molK}$. It is worth noting that the thermodynamic values obtained for the $\mathrm{C}_{70}$ case are affected by a higher error than those obtained for the $\mathrm{C}_{60}$ case, due to the difficulties observed for the determination of the constants at the lower temperatures, because the overlapping of the signals forced us to estimate the constants by deconvolution. With these data in hand, we concluded that the low enthalpies and relatively large entropies observed indicate that the encapsulation of fullerenes by $\mathbf{2}$ is assisted by the intrinsic entropic contribution (-T $\Delta S$ ), to afford negative free energy changes. Thus, the complexation is entropically favored by desolvation of the host and the guest. The complexation of $\mathrm{C}_{70}$ shows a greater value of $\Delta S$ due to the larger number of solvent molecules bound to $C_{70}$ relative to $C_{60}$, as a consequence of the larger molecular surface of the former. The endothermicity of the associations is explained by the large solvation enthalpies of the host and guest. E.g., experimental solvation energies of -30.5 and $-35.3 \mathrm{kcal} / \mathrm{mol}$ were reported for $\mathrm{C}_{60}$ and $\mathrm{C}_{70}$ respectively, in odichlorobenzene. ${ }^{[15]}$

Given the greater effective affinity of the metallocage 2 for $C_{70}$ over $\mathrm{C}_{60}$, we designed two competitive experiments aiming to provide practical experimental procedures for the separation of these two types of fullerenes. In the first experiment (Figure 4a), we suspended an equimolar mixture of $\mathrm{C}_{60}$ and $\mathrm{C}_{70}$ in acetone- $d_{6}$, and added one equivalent of 2 ; then the mixture was sonicated for $6 \mathrm{~h}$. The analysis of the solution by ${ }^{13} \mathrm{C}$ NMR and mass spectrometry, indicated that only $\mathrm{C}_{70}$ was trapped by 2 . The suspension was filtered off, and the black solid was redissolved in dichlorobenzene- $d_{4}$. The ${ }^{13} \mathrm{C}$ NMR of this sample confirmed the presence of the remaining pure $\mathrm{C}_{60}$ in this solution. In the second experiment (Figure $4 b$ ), a suspension of $\mathrm{C}_{60}$ and an equivalent amount of $\mathbf{2}$ were sonicated in acetone- $d_{6}$ until quantitative encapsulation of the fullerene. The presence of $\mathrm{C}_{60}$ inside the cavity of 2 was confirmed by ${ }^{13} \mathrm{C}$ NMR spectroscopy and mass spectrometry. Then, one equivalent of $\mathrm{C}_{70}$ was added to the mixture, and the suspension was sonicated for $6 \mathrm{~h}$. The analysis of the resulting solution indicated that $\mathrm{C}_{70}$ had replaced $\mathrm{C}_{60}$ in the interior of the cavity, while the analysis of the solid confirmed the release of $\mathrm{C}_{60}$. These two simple experiments illustrate how the metallocage 2 can be used as a convenient molecular receptor for selective fullerene binding and release, and thus practical applications for the purification of fullerenes may be envisaged.

a)
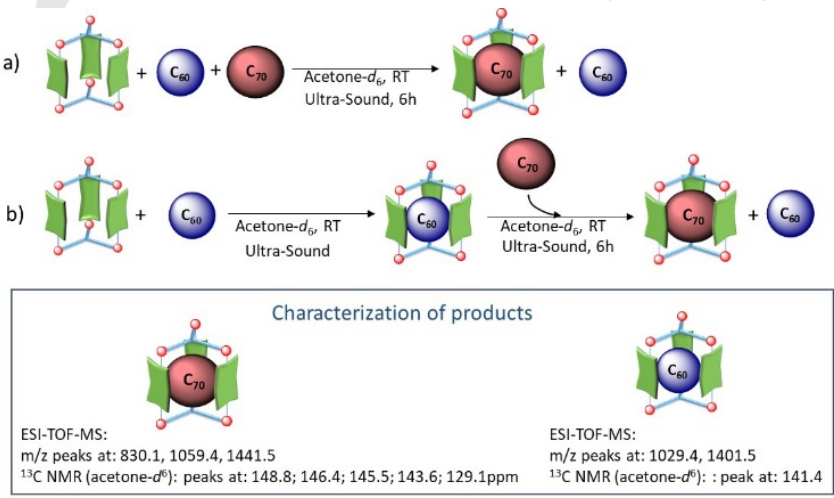

Figure 4. Schematic representation of competitive experiments, together with the characterization data of the resulting host:guest complexes formed. 


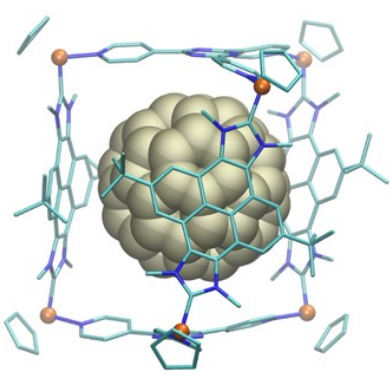

$\mathrm{C}_{60} @ 2$

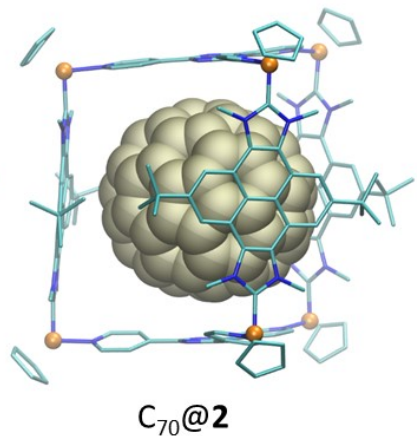

$\mathrm{C}_{70} @ 2$
Figure 5. DFT-optimized structures of $\mathrm{C}_{60} @ 2$ (left) and $\mathrm{C}_{70} @ 2$ (right).

We performed DFT (M06-L/Def2SVP in o-dichlorobenzene solvent continuum) and semi-empirical (PM7) studies (see SI for details) to obtain more information about the geometries and binding energies of the complexes produced by the encapsulation of $\mathrm{C}_{60}$ and $\mathrm{C}_{70}$ in 2 (Figure 5). According to the DFT calculations, the cage of $C_{70} @ 2$ retains the approximate $D_{3 \mathrm{~h}}$ symmetric shape of 2 , and the hexametallic prism of the calculated structure does not reveal significant structural distortions compared to the experimental structure of Figure 1. These observations are also confirmed by the effective volume of the cage of $\mathrm{C}_{70} @ 2\left(880 \AA^{3}\right)$, which is slightly smaller compared to that in the empty 2 (vide supra).

The optimized geometry of $\mathrm{C}_{60} @ 2$ reveals how the hexanickel molecular prism can adapt its shape to wrap around the smaller molecule of $\mathrm{C}_{60}$ by twisting the structure about the $z$ axis, thus yielding a molecular shape of the pseudo $D_{3 d}$ symmetry. This deformation of the cage closes the distance between the top and bottom TPT ligands and allows a tighter interaction between the surface of the fullerene and the polyaromatic walls of the cage. The twisting of the cage results in a very significant shrinkage of the effective volume, from $1028 \AA^{3}$ in 2 to $698 \AA^{3}$ in $\mathrm{C}_{60} @ 2 .^{[16]}$

The computational study provided data allowing to calculate the enthalpy and Gibbs energy of the substitution reaction: $\mathrm{C}_{60} @ 2$ + $\mathrm{C}_{70} \rightarrow \mathrm{C}_{70} @ 2+\mathrm{C}_{60}, \Delta \mathrm{H}=-3.8$ and $\Delta \mathrm{G}=-6.0 \mathrm{kcal} / \mathrm{mol}$ at $298 \mathrm{~K}$, in o-dichlorobenzene. The calculated substitution entropy, $\Delta S=$ $7.5 \mathrm{cal} \cdot \mathrm{mol}^{-1} \cdot \mathrm{K}^{-1}$ is the same as the difference between the experimental encapsulation entropies of $C_{60}$ and $C_{70}, \Delta S=7$ $\mathrm{cal} \cdot \mathrm{mol}^{-1} \cdot \mathrm{K}^{-1}$, although the excellent agreement is probably fortuitous. We note, however, that the calculated encapsulation enthalpy of $\mathrm{C}_{70}$ suggests a more favorable process than that of $\mathrm{C}_{60}$, whereas the experimental encapsulation enthalpies are practically the same for both fullerenes. The $\Delta H$ values are relatively small; thus, they can be influenced by both computational and experimental errors. Nevertheless, proposing that the larger $\mathrm{C}_{70}$ can be more favorably accommodated in $\mathbf{2} \mathrm{vs}$. the smaller $\mathrm{C}_{60}$ is not unreasonable.

\section{Conclusions}

In summary, we prepared a NHC-based molecular prism that acts as a selective receptor for $\mathrm{C}_{70}$ over $\mathrm{C}_{60}$, and facilitates the selective binding of the former from a mixture of the two. We also proved that the cage shows fullerene binding and release properties, with potential applications in the purification of mixtures of fullerenes. The supramolecular cage is able to modulate the size of the cavity for adapting to the shape of the fullerene host, thus it can be considered as a 'breathable' structure. Our work also demonstrates how NHC ligands can provide a competitive alternative to the classical Werner-type ligands in the design of supramolecular coordination cages for host-guest chemistry purposes.

\section{Acknowledgements}

We thank MINECO of Spain (CTQ2014-51999-P) and the Universitat Jaume I (P11B2014-02) for financial support. We are grateful to the Serveis Centrals d'Instrumentació Científica (SCIC) of the Universitat Jaume I for providing access to their facilities. We would like to thank Dr. Guisado-Barrios for his support in the determination of the X-ray crystal structure of 2.

Keywords: supramolecular coordination cage (SSC) $\bullet \mathrm{N}$ heterocyclic carbene $\cdot$ Host-guest chemistry $\bullet$ fullerene $\bullet$ selfassembly

[1] a) C. J. Brown, F. D. Toste, R. G. Bergman, K. N. Raymond, Chem. Rev. 2015, 115, 3012-3035; b) S. H. A. M. Leenders, R. Gramage-Doria, B. de Bruin, J. N. H. Reek, Chem. Soc. Rev. 2015, 44, 433-448; c) P. Dydio, J. N. H. Reek, Chem. Sci. 2014, 5, 2135-2145; d) T. S. Koblenz, J. Wassenaar, J. N. H. Reek, Chem. Soc. Rev. 2008, 37, 247-262; e) M. Raynal, P. Ballester, A. Vidal-Ferran, P. W. N. M. van Leeuwen, Chem. Soc. Rev. 2014, 43, 1660-1733; f) I. Sinha, P. S. Mukherjee, Inorg. Chem. 2018, DOI: 10.1021/acs.inorgchem.1027b03067.

[2] a) S. Dong, B. Zheng, F. Wang, F. Huang, Acc. Chem. Res. 2014, 47, 19821994; b) K. Ariga, H. Ito, J. P. Hill, H. Tsukube, Chem. Soc. Rev. 2012, 41, 5800-5835; c) B. Chen, S. Xiang, G. Qian, Acc. Chem. Res. 2010, 43, 1115-1124.

[3] A. Galan, P. Ballester, Chem. Soc. Rev. 2016, 45, 1720-1737.

[4] a) A. Schmidt, V. Molano, M. Hollering, A. Poethig, A. Casini, F. E. Kuehn, Chem. Eur. J. 2016, 22, 2253-2256; b) Y.-R. Zheng, K. Suntharalingam, T. C. Johnstone, S. J. Lippard, Chem. Sci. 2015, 6, 1189-1193; c) B. Therrien, in Chemistry of Nanocontainers, Vol. 319 (Eds.: M. Albrecht, F. E. Hahn), 2012, pp. 35-55; d) F. Schmitt, J. Freudenreich, N. P. E. Barry, L. JuilleratJeanneret, G. Suess-Fink, B. Therrien, J. Am. Chem. Soc. 2012, 134, 754757; e) N. P. E. Barry, O. Zava, P. J. Dyson, B. Therrien, Chem. Eur. J. 2011, 17, 9669-9677; f) O. Zava, J. Mattsson, B. Therrien, P. J. Dyson, Chem. Eur. J. 2010, 16, 1428-1431; g) B. Therrien, G. Suess-Fink, P. Govindaswamy, A. K. Renfrew, P. J. Dyson, Angew. Chem. Int. Ed. 2008, 47, 3773-3776; h) T. R. Cook, V. Vajpayee, M. H. Lee, P. J. Stang, K.-W. Chi, Acc. Chem. Res. 2013, 46, 2464-2474.

[5] a) A. M. Castilla, W. J. Ramsay, J. R. Nitschke, Acc. Chem. Res. 2014, 47, 2063-2073; b) G. H. Clever, P. Punt, Acc. Chem. Res. 2017, 50, 22332243; c) M. Han, D. M. Engelhard, G. H. Clever, Chem. Soc. Rev. 2014, 43, 1848-1860; d) C. Lescop, Acc. Chem. Res. 2017, 50, 885-894; e) S. Zarra, D. M. Wood, D. A. Roberts, J. R. Nitschke, Chem. Soc. Rev. 2015, 44, 419-432.

[6] a) T. K. Ronson, W. Meng, J. R. Nitschke, J. Am. Chem. Soc. 2017, 139, 9698-9707; b) C. Garcia-Simon, M. Costas, X. Ribas, Chem. Soc. Rev. 2016, 45, 40-62; c) N. Kishi, M. Akita, M. Yoshizawa, Angew. Chem. Int. Ed. 2014, 53, 3604-3607; d) C. Garcia-Simon, M. Garcia-Borras, L. Gomez, T. Parella, S. Osuna, J. Juanhuix, I. Imaz, D. Maspoch, M. Costas, X. Ribas, Nat. Commun. 2014, 5; e) P. D. Frischmann, S. H. M. Mehr, B. O. Patrick, 
F. Lelj, M. J. MacLachlan, Inorg. Chem. 2012, 51, 3443-3453; f) C. Mejuto, L. Escobar, G. Guisado-Barrios, P. Ballester, D. Gusev, E. Peris, Chem Eur. J. 2017, 23, 10644-10651; g) A. Sygula, Synlett 2016, 27, 2070-2080 h) T. Kawase, H. Kurata, Chem. Rev. 2006, 106, 5250-5273; i) D. Canevet E. M. Perez, N. Martin, Angew. Chem. Int. Ed. 2011, 50, 9248-9259.

[7] a) R. Govindarajan, R. Nagarajaprakash, B. Manimaran, Inorg. Chem. 2015 54, 10686-10694; b) E. M. Lopez-Vidal, A. Fernandez-Mato, M. D. Garcia M. Perez-Lorenzo, C. Peinador, J. M. Quintela, J. Org. Chem. 2014, 79, 1265-1270; c) C. Alvarino, E. Pia, M. D. Garcia, V. Blanco, A. Fernandez, C. Peinador, J. M. Quintela, Chem. Eur. J. 2013, 19, 15329-15335; d) V. Blanco, M. D. Garcia, A. Terenzi, E. Pia, A. Fernandez-Mato, C. Peinador, J. M. Quintela, Chem. Eur. J. 2010, 16, 12373-12380; e) C. Peinador, E. Pia, V. Blanco, M. D. Garcia, J. M. Quintela, Org. Lett. 2010, 12, 13801383; f) M. H. Yuan, F. Weisser, B. Sarkar, A. Garci, P. Braunstein, L. Routaboul, B. Therrien, Organometallics 2014, 33, 5043-5045; g) M. D Garcia, C. Alvarino, E. M. Lopez-Vidal, T. Rama, C. Peinador, J. M. Quintela, Inorg. Chim. Acta 2014, 417, 27-37; h) N. Kishi, Z. Li, Y. Sei, M. Akita, K. Yoza, J. S. Siegel, M. Yoshizawa, Chem. Eur. J. 2013, 19, 63136320 ; i) V. Martinez-Agramunt, S. Ruiz-Botella, E. Peris, Chem. Eur. J. 2017, 23, 6675-6681.

[8] N. Sinha, F. E. Hahn, Acc. Chem. Res. 2017, 50, 2167-2184.
[9] a) E. Mas-Marza, J. A. Mata, E. Peris, Angew. Chem. Int. Ed. 2007, 46, 3729 3731; b) S. Gonell, M. Poyatos, E. Peris, Chem. Eur. J. 2014, 20, 97169724; c) A. Prades, E. Peris, M. Alcarazo, Organometallics 2012, 31, 46234626; d) H. Valdes, M. Poyatos, E. Peris, Organometallics 2015, 34, 17251729; e) H. Valdes, M. Poyatos, E. Peris, Organometallics 2014, 33, 394401; f) S. Ibañez, M. Poyatos, E. Peris, Chem. Commun. 2017, 53, 37333736.

[10] a) D. Nuevo, S. Gonell, M. Poyatos, E. Peris, Chem. Eur. J. 2017, 23, 72727277; b) C. Biz, S. Ibañez, M. Poyatos, D. Gusev, E. Peris, Chem. Eur. J. 2017, 23, 14439-14444.

[11] S. Ibañez, M. Poyatos, E. Peris, Angew. Chem. Int. Ed. 2017, 56, 97869790.

[12] F. E. Hahn, C. Radloff, T. Pape, A. Hepp, Organometallics 2008, 27, 64086410.

[13] Estimation of volume was made using the swisspdb software, available at http://www.expasy.org/spdbv/.

[14] V. H. Le, M. Yanney, M. McGuire, A. Sygula, E. A. Lewis, J. Phys. Chem. B 2014, 118, 11956-11964.

[15] E. B. Stukalin, M. V. Korobov, N. V. Avramenko, J. Phys. Chem. B 2003, 107, 9692-9700.

[16] N. Guex, M. C. Peitsch, Electrophoresis 1997, 18, 2714-2723. 


\section{Entry for the Table of Contents}

\section{COMMUNICATION}

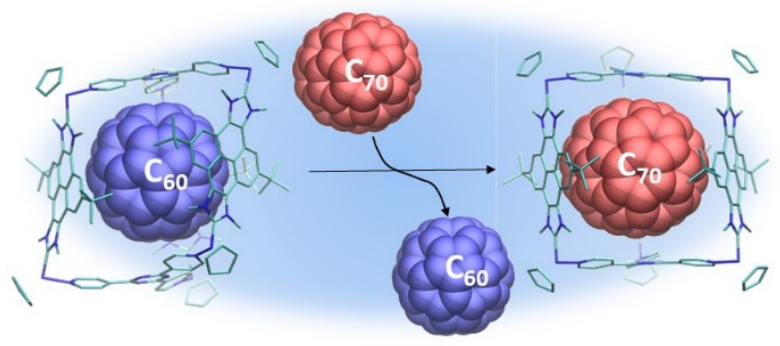

Víctor Martínez-Agramunt, Dmitry G. Gusev' and Eduardo Peris*

Page No. - Page No.

A shape-adaptable organometallic supramolecular coordination cage for the encapsulation of fullerenes

A nickel-conjoined organometallic prism cage shows highly selective complexation of $\mathrm{C}_{70}$ over $\mathrm{C}_{60}$. The supramolecular cage is able to modulate the size of the cavity for adapting to the shape of the fullerene host. 